\title{
Effects of Methamphetamine on the Twitch Response in the Rat Isolated Vas Deferens
}

\author{
Masanobu URABE, Hiromu KAWASAKI and Koichiro TAKASAKI \\ Department of Pharmacology. Miyazaki Medical College. \\ Miyazaki 889-16. Japan \\ Accepted July 29.1987
}

\begin{abstract}
The effect of methamphetamine, an indirectly acting sympathomimetic amine, on presynaptic adrenergic regulation in isolated rat vas deferens was studied by comparing it with those of tyramine, cocaine and clonidine. These drugs markedly attenuated the twitch response to electrical field stimulation in a concentration-dependent manner. The relative order of potency for the drugs was: clonidine $\left(10^{-10}-3 \times 10^{-8} \mathrm{M}\right)>$ methamphetamine $\left(10^{-8}-3 \times 10^{-6} \mathrm{M}\right)>$ tyramine $\left(10^{-7}-10^{-4} \mathrm{M}\right)>$ cocaine $\left(10^{-6}-3 \times 10^{-5} \mathrm{M}\right)$. Only tyramine $\left(3 \times 10^{-6}-10^{-4} \mathrm{M}\right)$ elicited a concentration-dependent contractile response, which was abolished by prazosin $\left(10^{-6} \mathrm{M}\right)$ and the reserpinization. The twitch inhibitory effect of these drugs was antagonized by yohimbine $\left(10^{-8}-10^{-6} \mathrm{M}\right)$. Both the methamphetamine- and tyramine-induced twitch inhibition were partially (about 50\%) attenuated by chronic reserpinization ( $3 \mathrm{mg} / \mathrm{kg}$. s.c., twice) in combination with alpha-methyl-p-tyrosine $(200 \mathrm{mg} / \mathrm{kg}$, s.c.. twice), while the clonidine-induced inhibition was not affected by this application at all, and the cocaine-induced twitch inhibition was abolished by the reserpinization. Both the clonidine- and tyramine-induced twitch inhibition were not affected by pretreatment with cocaine $\left(10^{-5} \mathrm{M}\right)$ in combination with estradiol $\left(4 \times 10^{-5} \mathrm{M}\right)$, whereas the effect of methamphetamine was slightly attenuated. These results suggest that methamphetamine as well as tyramine and cocaine indirectly activates presynaptic alpha-2 adrenoceptors via norepinephrine released from adrenergic nerves to inhibit the twitch response. It is also suggested that the inhibitory effects of methamphetamine and tyramine may be partially mediated by direct activation of presynaptic alpha- 2 adrenoceptors by themselves.
\end{abstract}

Indirectly acting sympathomimetic drugs such as amphetamine, methamphetamine. ephedrine or tyramine have been shown to facilitate the liberation of catecholamine from adrenergic nerve terminals $(1,2)$. Recently, it is generally accepted that the released endogenous norepinephrine may regulate its own release by stimulating presynaptic alpha-2 adrenoceptors (3-5). In the present experiment, the isolated fieldstimulated vas deferens of the rat was used as a model system to study the possible relationship between the twitch inhibitory effect of methamphetamine and presynaptic alpha-2 adrenoceptors. The motor transmission in the vas deferens, independently of the adrenergic or non-adrenergic nature of the nerve terminals $(6-8)$, is modulated by inhibitory presynaptic alpha- 2 adrenoceptors (9, 10). Ambach et al. (11) and Marshall et al. (12) have reported that tyramine might indirectly inhibit adrenergic neurotransmission via presynaptic alpha-2 adrenoceptors activated by norepinephrine released by itself. Neuronal monoamine uptake blocking agents such as cocaine, desipramine. imipramine and related compounds have also been shown to inhibit adrenergic neurotransmission via the increased concentration of norepinephrine in the synaptic gaps (13-15). Furthermore, methamphetamine has been shown to have a potent 
cocaine-like action $(2,16)$.

In the present study, therefore, we investigated the effect of methamphetamine on the presynaptic alpha-2 adrenoceptor of the rat vas deferens. This study was also designed to compare the effects of tyramine. clonidine (selective alpha-2 adrenoceptor agonist) and cocaine.

\section{Materials and Methods}

The vas deferens of Wistar rats, weighing 250-350 g. were carefully dissected free from the surrounding connective tissue. A section of $2.5 \mathrm{~cm}$, including mainly the prostatic portion of the tissue, was submerged in a bath of Krebs' solution aerated with a mixture of $95 \% \mathrm{O}_{2}+5 \% \mathrm{CO}_{2}$. maintained at $30^{\circ} \mathrm{C}$. The modified Krebs' bicarbonate solution of the following composition was used $(\mathrm{mM}): \mathrm{NaCl}, 119 ; \mathrm{KCl}, 4.7 ; \mathrm{CaCl}_{2}, 2.5$ : $\mathrm{KH}_{2} \mathrm{PO}_{4}, 1.2 ; \mathrm{MgSO}_{4}, 0.6 ; \mathrm{NaHCO}_{3}, 25$; glucose, 11. Longitudinal contractions of the tissue were isometrically measured with a force-displacement transducer (Nihon Kohden, FD-1T) and recorded on a polygraph (Nihon Kohden. RM-25). After a stable tension (1 g load) was obtained, transmural nerve stimulation ( $3 \mathrm{msec}$ in duration, supramaximal voltage, $0.1 \mathrm{~Hz}$ ) was applied via platinum ring-electrodes. After a constant twitch response was obtained, the agonists were added to the bath in a cumulative concentration schedule. Three to 5 min intervals were allowed to elapse between the successive increase of concentrations to enable the full inhibitory effects of the agonists to develop. In the experiments using antagonists, the employed control concentrationresponse curves and those in the presence of antagonists were obtained in separate preparations since the full recovery from the twitch inhibition by the maximally effective concentration of agonists was not obtained by washout. The antagonists were allowed to contact with the vas deferens for $15 \mathrm{~min}$ prior to the addition of agonists. Special experimental procedures are described in detail under the Results.

Data were analyzed by using Student's $t$-test. The following drugs were used in this study: $d$-methamphetamine hydrochloride (Dainihon Seiyaku), tyramine hydrochloride
(Wako Junyaku), clonidine hydrochloride (Boehringer Ingelheim), I-norepinephrine hydrochloride (Sigma), /-phenylephrine hydrochloride (Sigma), yohimbine hydrochioride (Wako Junyaku), prazosin hydrochloride (Pfizer), cocaine hydrochloride (Takeda Seiyaku), estradiol (Merck), reserpine (Daiichi Seiyaku) and alphamethyl p-tyrosine hydrochloride (Aldrich). All drugs were dissolved in saline $(0.9 \%$ $\mathrm{NaCl} \mathrm{W} / \mathrm{v}$ ) and diluted in Krebs' solution.

\section{Results}

Effects of sympathomimetic drugs on the twitch response: The transmural nerve stimulation of isolated rat vas deferens caused rapid twitch contractions without changes in the resting tension. The mean value of the twitch response before drug administration was $1.6 \pm 0.04 \mathrm{~g}(n=62)$. As shown in Fig. 1, the twitch responses were con centration-dependently inhibited by methamphetamine, tyramine, clonidine and cocaine. These drugs at any of the concentrations used, however, did not attenuate the exogenous norepinephrine $\left(5 \times 10^{-6} \mathrm{M}\right)$ induced contraction (data not shown). In contrast, phenylephrine, a selective alpha-1 adrenoceptor agonist, failed to inhibit the twitch response and rather tended to potentiate it. On the other hand, only tyramine at doses of more than $3 \times 10^{-6} \mathrm{M}$ produced a concentration-dependent contractile response, which was abolished by pretreatment of prazosin $\left(10^{-3} \mathrm{M}\right)$, a selective alpha-1 adrenoceptor antagonist, or reserpinization (data not shown). Figure 2 and Table 1 show concentration-response curves and $\mathrm{pD}_{2}$ values for the twitch inhibitory effect of these sympathomimetic drugs used in the present study. The relative order of potency for these drugs at the inhibition of twitch response was: clonidine>methamphetamine $>$ tyramine $>$ cocaine. The maximal inhibitions (\%) by clonidine, methamphetamine, tyramine and cocaine were $92.94 \pm 1.11,87.91 \pm$ 0.93. $81.54 \pm 1.05$ and $64.71 \pm 3.07$, respectively.

Effects of alpha-adrenoceptor antagonists on the twitch inhibition: As shown in Fig. 1. maximal twitch inhibitions of methamphetamine $\left(3 \times 10^{-6} \mathrm{M}\right)$, tyramine $(3 \times$ 


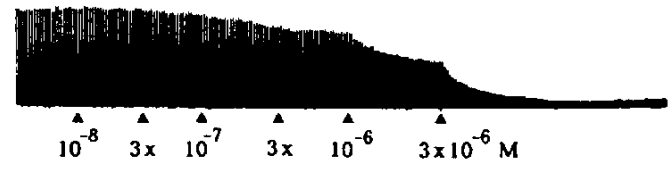

Methamphetamine

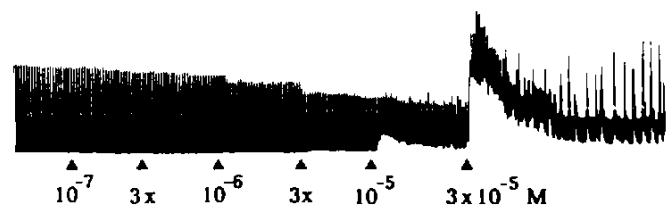

Tyramine

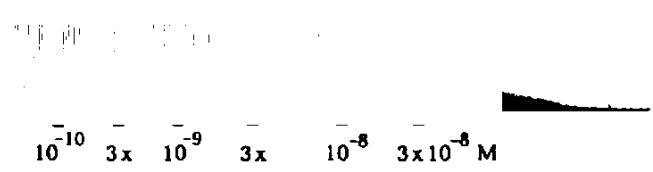

Clonidine

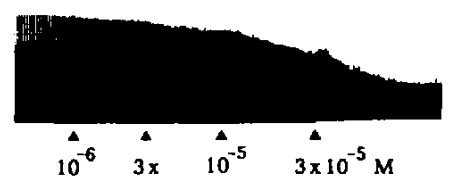

Cocaine

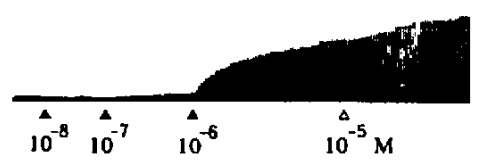

Yohimbine

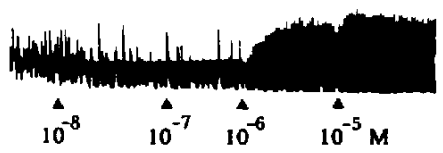

Yohimbine

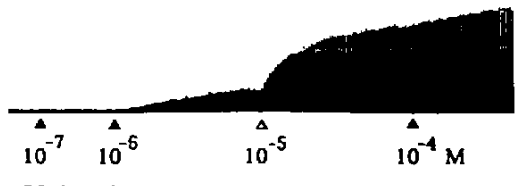

Yohimbine

Fig. 1. Typical traces of twitch inhibitory effect caused by methamphetamine, tyramine, clonidine and cocaine, and restoration of the inhibition by yohimbine. Each drug was cumulatively added to the tissue bath at the points indicated.

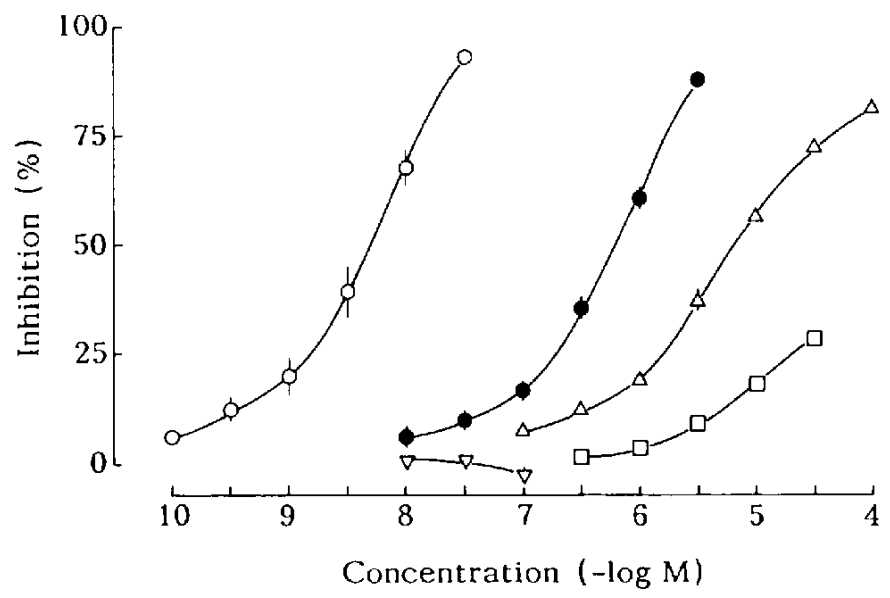

Fig. 2. Concentration-response curves of the twitch inhibitory effect for clonidine (O: $n=8)$, methamphetamine $(\mathrm{O}: n=13)$, tyramine $(\triangle: n=11)$, cocaine $([\because: n=8)$ and phenylephrine $(\nabla: n=6)$ in the rat isolated vas deferens. Vertical bars show S.E.M. 
Table 1. Orders of potencies for alpha adrenoceptor agonists in the inhibition of twitch response to field stimulation in the rat vas deferens

\begin{tabular}{|c|c|c|c|}
\hline Agonist & $n$ & $\rho D_{2}$ & $(95 \%$ C.L. .) \\
\hline Methamphetamine & 13 & $6.26 \pm \overline{0.04}$ & $\overline{(6.17}-6.35)$ \\
\hline Tyramine & 11 & $5.18 \pm 0.04$ & $(5.09-5.27)$ \\
\hline Clonidine & 8 & $8.35 \pm 0.09$ & $(8.14-8.56)$ \\
\hline Cocaine & 8 & $4.89 \pm 0.09$ & $(4.68-5.10)$ \\
\hline
\end{tabular}

*95\% Confidence Limits.

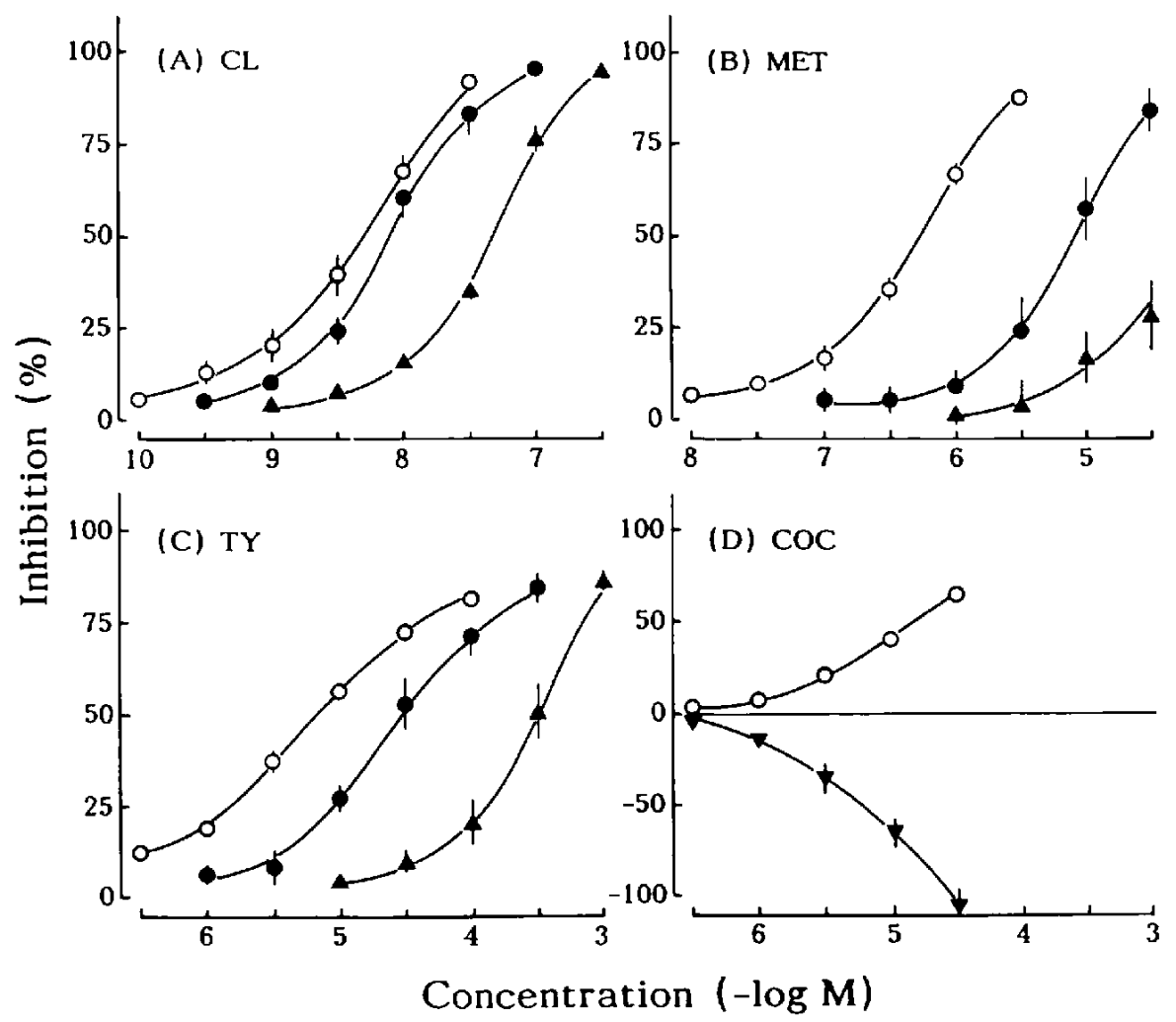

Fig. 3. Antagonism by yohımbıne against the twitch inhibitory effects of (A) clonidine (CL), (B) methamphetamine (MET), (C) tyramine (TY) and (D) cocaine (COC) in the electrically stimulated rat vas deferens. (O) Control, (O) after treatment of yohimbine $10^{-7} \mathrm{M} .(\boldsymbol{\nabla})$ after treatment of yohimbine $3 \times 10^{-7} \mathrm{M},(\mathbf{\Delta})$ after treatment of yohimbine $10^{-6} \mathrm{M}$. Vertical bars show S.E.M.

$\left.10^{-5} \mathrm{M}\right)$, clonidine $\left(3 \times 10^{-8} \mathrm{M}\right)$ and cocaine $\left(3 \times 10^{-5} \mathrm{M}\right)$ were markedly restored by subsequent administration of yohimbine, a selective alpha-2 adrenoceptor antagonist. but not by prazosin, in a concentrationdependent manner. Figure 3 shows that the concentration-response curves for clonidine. methamphetamine and tyramine were shifted parallelly and concentration-depen- dently to the right by pretreatment of yohimbine $\left(10^{-7} \mathrm{M}\right.$ and $\left.10^{-\hat{0}} \mathrm{M}\right)$ without alteration of the maximal twitch inhibition. The interaction between methamphetamine and yohimbine shows competitive antagonism since Schild plots gave linear regression in this case. The $\mathrm{pA}_{2}$ value was 8.25 and the slope of the regression line was 0.969 . Especially, in the presence of yohim- 
bine $\left(3 \times 10^{-7} \mathrm{M}\right)$, cocaine did not inhibit the twitch response and rather potentiated it. On the other hand, pretreatment of prazosin $\left(10^{-\hat{o}} \mathrm{M}\right)$ failed to antagonize the twitch inhibition by these drugs (data not shown).

Effect of cocaine on the twitch inhibition: Cocaine $\left(10^{-5} \mathrm{M}\right)$ in combination with estradiol $\left(4 \times 10^{-5} \mathrm{M}\right)$. an extraneuronal monoamine uptake blocker, was applied 15 min before addition of methamphetamine. tyramine or clonidine. As shown in Fig. 4, both the clonidine- and tyramine-induced twitch inhibitions were not affected by cocaine treatment. Figure 4 also shows that cocaine caused a significant shift $(P<0.05)$ to the right in the inhibitory response curve to methamphetamine, but it remained parallel to the control curve

Effect of reserpinization on the twitch inhibition: To deplete the tissue storage of norepinephrine, the rats were chronically treated in combination with reserpine ( 3 $\mathrm{mg} / \mathrm{kg}$. s.c., twice) at $48 \mathrm{hr}$ and $24 \mathrm{hr}$, and alpha-methyl-p-tyrosine, a tyrosine hydroxylase inhibitor, $(200 \mathrm{mg} / \mathrm{kg}$, s.c., twice) at $15 \mathrm{hr}$ and $3 \mathrm{hr}$ prior to the start of the experiment. This treatment has been shown to deplete norepinephrine content in the vas deferens more than $99 \%$ (12). In the reserpinized rats, the field stimulation-induced twitch responses of vas deferens were attenuated approximately to half that of the nontreated preparation. As shown in Fig. 4. the clonidine-induced twitch inhibition was not altered by the reserpinization. Both the methamphetamine- and tyramine-induced twitch inhibitions, however, were markedly attenuated but not abolished by the reserpinization, and approximately $50 \%$ of the maximal twitch inhibitions of the control
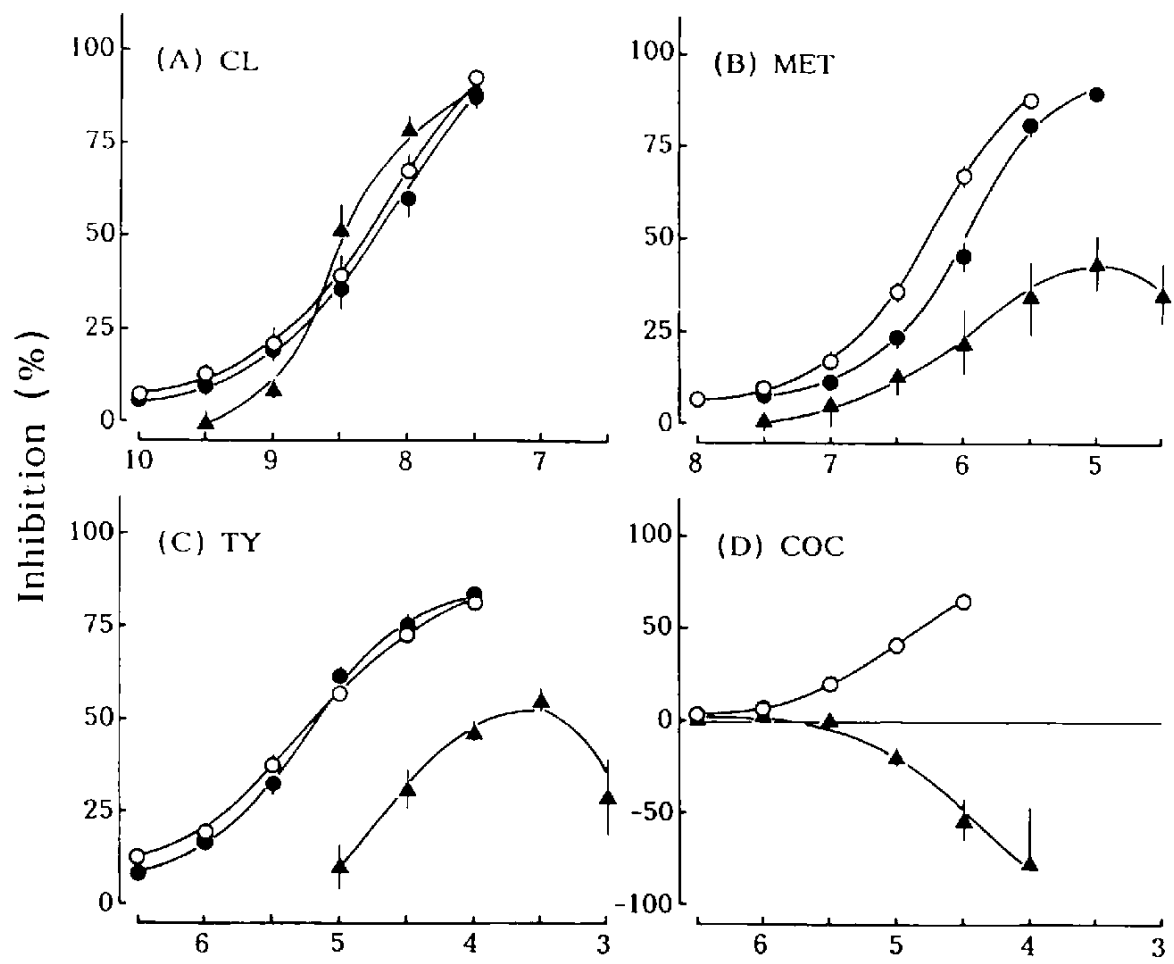

Concentration $(-\log M)$

Fig. 4. The influences of cocaine and chronic reserpinization (see results) against the twitch inhibitory effects of (A) clonidine (CL), (B) methamphetamine (MET), (C) tyramine (TY) and (D) cocaine (COC) in the rat isolated vas deferens. (O) Control, (O) after treatment of $10^{-6} \mathrm{M}$ cocaine plus $4 \times 10^{-5} \mathrm{M}$. estradiol ( $\mathbf{A}$ ) after treatment of reserpine plus alpha-methyl-p-tyrosine. Vertical bars show S.E.M. 
were still produced by methamphetamine and tyramine. In these cases, yohimbine $\left(10^{-6} \mathrm{M}\right)$ was still able to restore the remaining twitch inhibitions. In contrast, the cocaine-induced twitch inhibition was abolished by the reserpinization, similar to vohimbine treatment.

\section{Discussion}

In the present studies, methamphetamine caused a potent inhibition of the twitch response to transmural nerve stimulation of the rat vas deferens. This appears likely to be due to an action on presynaptic alpha- 2 adrenoceptors, since the effect of methamphetamine is 1) mimicked by clonidine but not phenylephrine, 2) competitively antagonized without alteration of the maximal effect by yohimbine but unaffected by prazosin, and 3) methamphetamine did not attenuate the exogenous norepinephrineinduced contration.

In the present experiments, it was found that the twitch inhibitory effect of methamphetamine was about 100 times less potent than that of clonidine and about 10 times more potent than that of tyramine, and cocaine had a very weak one. The difference of potency of the twitch inhibitory effect between clonidine and cocaine may reflect a qualitative difference of action on presynaptic alpha-2 adrenoceptors, that is, clonidine being able to directly activate the receptors $(9.17,18)$ and cocaine indirectly activating the receptors via catecholamine accumulated in the synaptic gaps $(13,14)$. This contention is further supported by the present findings that the clonidine-induced twitch inhibitory response was unaffected by both pretreatment with cocaine and chronic reserpinization, while the cocaine-induced twitch inhibition was abolished by the reserpinization, indicating the successful depletion of catecholamines by reserpine.

In the case of methamphetamine, in addition to a tyramine-like catecholamine releasing action, this drug has a potent cocaine-like action (catecholamine reuptake blocking action) (2, 16). Furthermore, the possibility of the direct stimulant action on alpha-adrenoceptors by tyramine, amphetamine, ephedrine or methamphetamine has been reported (19-22). On the other hand. Ambach et al. (11) and Marshall et al. (12) have concluded that the tyramine-induced twitch inhibition in the vas deferens of mouse results from an indirect activation of presynaptic alpha-2 adrenoceptors, because the inhibition was abolished either by pretreatment with cocaine or by norepinephrine depletion with reserpine.

Recently, it has been reported that the twitch response of the rat vas deferens caused by field stimulation could be at least partly mediated by an action upon "nonadrenergic neurons" (6-8). which is also modulated by inhibitory presynaptic alpha- 2 adrenoceptors $(9,10)$. In the present experiments, the twitch responses still remained after reserpinization at a level of about $50 \%$ that of the non-treated preparation, suggesting that this remaining twitch response is non-adrenergic in nature. In the experiments under reserpinization, clonidine, methamphetamine and tyramine but not cocaine still caused the twitch inhibition, although the inhibitory effects of methamphetamine and tyramine were extensively attenuated to approximately $50 \%$ that of the control. This twitch inhibition that was observed in the reserpinized preparation is presumably due to a direct action on presynaptic alpha-2 adrenoceptors, since the inhibitory effect was still effectively restored by yohimbine, and indirect action of methamphetamine and tyramine mediated by norepinephrine should not be produced under this condition.

If methamphetamine or tyramine has mainly an indirect action and partially a direct one on presynaptic alpha-2 adrenoceptors, the methamphetamine- or tyramine-induced twitch inhibition should be attenuated by cocaine treatment to an extent similar to that observed after reserpinization. However, the present experiments showed that the tyramine-induced twitch inhibitory effect was not affected at all by pretreatment with cocaine, and the methamphetamine-induced one was moderately but significantly attenuated by cocaine However, an explanation for this discrepancy is that the direct action of methamphetamine and tyramine on the presynaptic alpha-2 
adrenoceptors may be intensified by cocaine. The treatment with cocaine probably inhibits an uptake of both drugs into adrenergic nerve endings (23) so that they can more potently bind with the presynaptic receptors under this condition. It appears that the attenuation of an indirect factor by cocaine is masked by the increased direct action of both drugs. On the other hand, the methamphetamine-induced twitch inhibition was attenuated by cocaine pretreatment as compared with that of tyramine. In this regard, it has been reported that methamphetamine has a potent cocaine-like action. whereas tyramine has small one $(2,16)$. The cocaine-like action of methamphetamine may be ineffective in the preparation treated with cocaine. where catecholamine reuptake is already maximally blocked by cocaine. These findings indicate that the methamphetamine-induced twitch inhibition may be mediated by a cocaine-like action, tyraminelike aciion and direct stimulatory action by itself on presynaptic alpha-2 adrenoceptors.

In conclusion, these results suggest that methamphetamine as well as tyramine and cocaine inhibits the twitch response to field stimulation by activation of presynaptic alpha-2 adrenoceptors indirectly via norepinephrine released from nerve terminals, whereas clonidine stimulates the receptors directly. It is also suggested that the inhibitory effects of methamphetamine and tyramine may be partially mediated by a direct stimulatory action on presynaptic alpha-2 adrenoceptors. Therefore, in isolated rat vas deferens, there may be some differences in the mechanism of the twitch inhibitory effect among clonidine, methamphetamine, tyramine and cocaine.

\section{References}

1 Burn, H.J. and Rand, M.J.: The action of sympathomimetic amines in animals treated with reserpine. J. Physiol. (Lond.) 144, 314-336 (1958)

2 Axelrod, J., Hertting, G. and Potter. L.: Effect of drugs on the uptake and release of ${ }^{3} \mathrm{H}$ norepinephrine in the rat heart. Nature 194, 297 (1962)

3 Vizi, E.S., Somogyi, G.T., Hadhazy, P. and Knoll, J.: Effect of duration and frequency of stimulation on the presynaptic inhibition by $\alpha$ - adrenoceptor stimulation of the adrenergic transmission. Naunyn Schmiedebergs Arch. Pharmacol. 280, 79-91 (1973)

4 Langer, S.Z.: Presynaptic regulation of the release of catecholamine. Pharmacol. Rev. 32, 337-362 (1981)

5 Starke, K.: Presynaptic receptors. Annu. Rev. Pharmacol. Toxicol. 21, 7-30 (1981)

6 McGrath, J.C.: Adrenergic and 'non-adrenergic' components in the contractile response of the rat vas deferens to a single indirect stimulus. J. Physiol. (Lond.) 283, 23-39 (1978)

7 Brown, D.A., Docherty, J.R., French, A.M., MacDonald, A., McGrath, J.C. and Scott, N.C.: Separation of adrenergic and non-adrenergic contractions to field stimulation in the rat vas deferens. Br. J. Pharmacol. 79, 379-393 (1983)

8 French, A.M. and Scott, N.C.: Evidence to support the hypothesis that ATP is a cotransmitter in rat vas deferens. Experientia 39 , 264-266 (1983)

9 Drew, G.M.: Pharmacological characterization of the presynaptic $\alpha$-adrenoceptor in the rat vas deferens. Eur. J. Pharmacol. 42, 123-130 (1977)

10 Illes, P. and Dörge, L.: Mechanism of $\alpha_{2}$ adrenergic inhibition of neuroeffector transmission in the mouse vas deferens. Naunyn Schmiedebergs Arch. Pharmacol. 328, 241-247 (1985)

11 Ambach, N., Dunk, L.P., Verney, J. and Zar, M.A.: Inhibition of post-ganglionic motor transmission in vas deferens by indirectly acting sympathomimetic drugs. J. Physiol. (Lond.) 277, 433-456 (1972)

12 Marshall, I., Nasmyth, P.A. and Shepperson, N.B.: The effects of release and depletion of endogenous noradrenaline on the transmission of impulses in the mouse vas deferens. Br. J. Pharmacol. 64, 145-152 (1978)

13 Grant, K., Marshall, I. and Nasmyth, P.A.: Cocaine and presynaptic $\alpha$-adrenoceptor regulation of noradrenaline release in response to one and two pulses. Br. J. Pharmacol. 69, 344 (1980)

14 Lottic, V.C., Raymond, S.L. and Kling, P.: Preand postsynaptic adrenergic activation by norepinephrine reuptake inhibitors in the fieldstimulated rat vas deferens. Life Sci. 29, 633-639 (1981)

15 Garcia-Sevilla, J.A. and Zubieta, J.K.: Activation and desensitization of presynaptic $\alpha_{2}$-adrenoceptors after inhibition of neurcnal uptake by antidepressant drugs in the rat vas deferens. Br. J. Pharmaco!. 89, 673-683 (1986)

16 Burgen, A.S.V. and Iversen, L.L.: The inhibition 
of noradrenaline uptake by sympathomimetic amines in the rat isolated heart. Br. J. Pharmacol. 25, 34-49 (1965)

17 Starke, K., Endo, T. and Taube, H.D.: Pre- and post-synaptic components in effect of drugs with $\alpha$-adrenoceptor affinity. Nature 254, 440441 (1975)

18 Doxey, J.C., Smith, C.F.C. and Walker, J.M.: Selectivity of blocking agents for pre- and postsynaptic $\alpha$-adrenoceptors. Br. J. Pharmacol. $60,91-96$ (1977)

19 Lee, T.J.-F., Araki, H. and Su. C.: Tyramineinduced contractions in the rabbit ear and basilar arteries. J. Cardiovasc. Pharmacol. 3. 965-976 (1981)

20 Downing, O.A.: Effect of amphetamine on the transmission of repetitive impulses through isolated superior cervical ganglion of the rat. $\mathrm{Br}$. J. Pharmacol. 44, 71-79 (1972)

21 Bauer, V.: Distribution and types of adrenoceptors in the guinea-pig ileum: the action of $\alpha$ - and $\beta$ adrenoceptor agonists. Br. J. Pharmacol. 72, 201-210 (1981)

22 Yamamoto, R. and Takasaki, K.: Involvement of presynaptic $\alpha_{2}$-adrenoceptors in the depressor response produced by repeated administration of dextro-methamphetamine. J. Auton. Pharmacol. $3,78-88(1983)$

23 Schümann, H.J. and Philippu, A.: Release of catecholamines from isolated medullary granules by sympathomimetic amines. Nature 193, 890891 (1962) 